\title{
МОДЕЛЬ ДОКУМЕНТАЦИОННОГО ОБЕСПЕЧЕНИЯ ПРОЦЕССА УПРАВЛЕНИЯ ИНТЕЛЛЕКТУАЛЬНОЙ СОБСТВЕННОСТЬЮ
}

\section{MODEL OF DOCUMENTATION SUPPORT OF THE INTELLECTUAL PROPERTY MANAGEMENT PROCESS}

\section{K. Gerasimov \\ E. Shkodina}

Summary. In the era of scientific and technological progress, the development of innovations, it is extremely important to pay attention to the management of intellectual property. In this article, the authors analyze in detail the sub-process of intellectual property management as part of the innovation management process. The subprocess is considered from the point of view of key management functions, functional and managerial tasks. The authors define the main stages, resources of the activity, as well as the necessary input and output attributes for the implementation of this sub-process in general and management functions in particular. As a result of the work, the authors have compiled a document flow model that ensures the efficiency and continuity of the sub-process under consideration.

Keywords: management function, innovation, intellectual property, sub-process, task, document flow.
B эпоху активно развивающегося научно-технического прогресса возрастает актуальность концепции процесса управления инновациями. Данное направление имеет место быть не только в производственной сфере, но и во многих других, например, в финансовой.

Процесс управления инновациями представляет собой комплекс взаимосвязанных подпроцессов, основная цель которых, создание уникального продукта [1].

В рамках процесса управления инновациями, авторами были выделены и описаны 11 основных подпроцессов: «управление потребностью в инновациях; управление приобретением инноваций; управление инновационными идеями; управление экспериментальными исследованиями; управление прикладными исследованиями; управление опытно-конструкторскими работами; управление инновационным потенциалом; управление внедрением инноваций; управление распространением инноваций; управление экономи-
Герасимов Кирилл Борисович

Д.э.н., профессор, Самарский национальный исследовательский университет имени академика С.П. Королёва 270580@bk.ru

Шкодина Елизавета Сергеевна Самарский национальный исследовательский университет имени академика С.П. Королёва shkodina.elizaveta@yandex.ru

Аннотация. В эпоху научно-технического прогресса, развития инноваций крайне важно уделять внимание управлению интеллектуальной собственностью. В данной статье авторы подробно анализируют подпроцесс управления интеллектуальной собственностью в рамках процесса управления инновациями. Подпроцесс рассматривается с точки зрения ключевых функций менеджмента, функционально-управленческих задач. Авторы определяют основные этапы, ресурсы деятельности, а также необходимые входные и выходные атрибуты для осуществления этого подпроцесса в целом и функций управления в частности. В результате работы авторами была составлена модель документооборота, обеспечивающая эффективность и непрерывность рассматриваемого подпроцесса.

Ключевые слова: функция управления, инновации, интеллектуальная собственность, подпроцесс, задача, документооборот.

кой инноваций; управление интеллектуальной собственностью» $[2,3]$.

В ходе данной статьи авторы предполагают проанализировать процесс управления инновациями, а также связанный с ним подпроцесс управления интеллектуальной собственностью, с точки зрения его базовых характеристик, технологий функциональных задач, а также модели документооборота.

Под управлением инновациями следует понимать мероприятия, реализуемые на протяжении процессов разработки, создания, производства, внедрения и эксплуатации инновационной продукции [4]. Управление инновациями в организациях требует системного подхода, соответственно, необходимо создать рациональную и последовательную систему управления инновациями.

Процесс управления инновациями позволит организации выполнять ключевые управленческие задачи: поддерживать уровень конкурентоспособности орга- 
низации, максимизировать прибыль и т.д. Именно поэтому так важно встроить инновационную бизнес-модель в существующую организацию [5].

Рассмотрение процесса управления инновациями логично начать с определения цели. Целью данного процесса является создание качественно нового продукта или усовершенствование уже существующего (улучшающие инновации).

Рассмотрим некоторые определения формулировки данного процесса:

- по мнению В.В. Курбатова инновационный процесс включает в себя последовательные этапы преобразования научно-исследовательской идеи в готовый(конечный) продукт [6];

- Д.М. Степаненко считает, что процесс управления инновациями представляет собой совокупность действий, проведение которых необходимо для того, чтобы создать практически используемый инновационный продукт [7].

Следует отметить, что функционирование любого процесса или подпроцесса можно разделить на основные атрибуты. На основании работы [8], авторами описаны вход, выход, а также основные этапы процесса управления инновациями.

Вход (назначение) процесса управления инновациями - необходимость в создании инновационного продукта, ресурсы.

Основные преобразования (основные этапы):

1. Формулирование инновационной идеи.

2. Проведение научных исследований.

3. Проведение экспериментальных испытаний

4. Разработка инновации

5. Коммерциализация инноваций, оценка инновации

6. Реализация на рынке и эксплуатация

7. Контроль за соблюдением прав

Выход (результаты) процесса управления инновациями - Конечный инновационный продукт, защищенный с правовой точки зрения

Для реализации основных операций в рамках процесса управлениями инновациями, используются различные группы ресурсов [9]:

- материальные ресурсы: сырье, вспомогательные материалы, технологическое и информационного оборудование, необходимое для разработки и производства инновационной продукции;

- информационные ресурсы: специализированная литература, медиа, государственные Интернет-ресурсы;
- методические ресурсы: должностные инструкции, внутренняя документация, планы;

- трудовые ресурсы: руководитель проекта, сотрудники научно-технического отдела, инженеры-конструкторы, экономисты;

- технические ресурсы: компьютер, ноутбук;

- правовые ресурсы: нормативно-правовые акты (федеральные законы, постановления правительства и т.д.).

Ранее в работе [2] авторами были обозначены основные подпроцессы процесса управления инновациями. Рассмотрим наиболее подробно подпроцесс «Управление интеллектуальной собственностью».

Подпроцесс управления интеллектуальной собственностью включает в себя как правовой, так экономический подтекст [10]. Исследователи вкладывают следующий смысл в определение данного подпроцесса: деятельность, наступающая после разработки инновационного продукта и заключающаяся в оценке его стоимости, продвижении и правовой защите.

Для функционирования данного подпроцесса используются следующие виды ресурсов:

- материальные ресурсы: оборудование, станки, сырье;

- информационные ресурсы: медиа, юридические заключения, учебные пособия;

- методические ресурсы: должностные инструкции;

- трудовые ресурсы: руководитель проекта, экономисты, юристы, аудиторы, маркетологи;

- технические ресурсы: компьютер, планшеты;

- правовые ресурсы: Гражданский кодекс Российской Федерации (часть четвертая, раздел VII. Права на результаты интеллектуальной деятельности и средства индивидуализации), ФКЗ от 31.12.1996 N1-ФК3 Ст. 26.1. Суд по интеллектуальным правам, ФК3 от 28.04.1995 N1-ФК3 Ст. 43.4. Полномочия Суда по интеллектуальным правам «О государственной политике в области охраны авторского права и смежных прав»; «О мерах по реализации прав авторов произведений, исполнителей и производителей фонограмм на вознаграждение за воспроизведение в личных целях аудиовизуального произведения или звукозаписи произведения».

Следует отметить, что для осуществления подпроцесса управления интеллектуальной собственностью требуется большее разнообразие трудовых ресурсов. В первую очередь, это связно с тем, что деятельность по управлению интеллектуальной собственностью включает в себя основное направление - правовое 
(оно позволяет закрепить право собственности за автором, а также защитить это право в дальнейшем), а также экономическое.

Для того, чтобы оценить уровень реализации подпроцесса авторами были предложены основные параметры и их характеристики:

- периодичность выполнения: в рамках каждого инновационного процесса;

- критерии качества: сотрудничество с квалифицированными юристами, правильное документарное оформление интеллектуальной собственности;

- Критерии эффективности: охрана (защищенность) результата, непоколебимость прав на объекты интеллектуальной собственности (ИС).

В рамках подпроцесса управления интеллектуальной собственностью выделяют 9 основных функциональных задач управления [11]. Для реализации каждой из них необходимо использовать комплекс документов, позволяющих осуществить внутренние операции. Авторы предлагают рассмотреть на примере трех функциональных задач управления: контроль интеллектуальной собственности, учет интеллектуальной собственности, а также нормирование интеллектуальной собственности.

Нормирование интеллектуальной собственности представляет собой достаточно специфичный процесс, так как его сложно регламентировать и практически невозможно спрогнозировать сроки получения результата инновационного процесса. Он напрямую зависят от множества факторов, в том числе и от морального, и физического состояния исследователя (разработчика) [12]. Также существует риск получения негативного результата.

По мнению авторов для того, чтобы организовать процесс нормирования труда, в первую очередь, необходимо отталкиваться от трудового законодательства для того, чтобы, например, определить допустимые часы работы.

Авторы предполагают, что в совокупности с государственными нормативами и нормативно-правовыми актами представляется возможным разработать систему нормирования (например, определить время, которое требуется уделять на научные-исследования (как отдельно взятый подпроцесс).

Следует отметить, что несмотря на всю непредсказуемость, в научно-исследовательской деятельности наблюдается цикличность, закономерность. Несмотря на это, по мнению, авторов для правильного нормиро- вания управления интеллектуальной собственностью необходимо разрабатывать персональную программу для каждого участника интеллектуальной деятельности.

Для наиболее наглядного восприятия авторами была представлена технология решения функциональной задачи управления «Нормирование интеллектуальной собственности»:

- входные документы: ТК РФ, план НИР, план производства, бизнес-план, предложения по внесение изменений в структуру нормирования;

- процедуры решения:

1. Принятие решения о нормировании подпроцесса управления интеллектуальной собственностью;

2. Анализ входных документов;

3. Определение эталонных показателей подпроцесса;

4. 5.Мониториг результативности сотрудников и оценка квалификации;

5. Определение методологии;

6. Разработка системы нормирования;

7. Утверждение индивидуальных нормативов для сотрудников инновационной деятельности.

- выходные документы: приказ, включающий индивидуальные нормативы для сотрудников

Следующая функциональная задача управления учет интеллектуальной собственности. Учет интеллектуальной собственности вызывает множество споров. Так как интеллектуальной собственности является нематериальным активом, то в первую очередь, встает вопрос о том, как ее оценить. Интеллектуальная собственность приобретает свою ценность как в процессе передачи прав на пользование третьим лицам (продажа франшизы, лицензии) или же ее дальнейшее использовании в ходе производственного цикла.

Рассмотрим технологию решения функциональной задачи управления «Учет интеллектуальной собственности»:

- входные документы: ПБУ 14/2007, ГК ст. 1225, баланс за последний отчетный период, Учетная политика организации, методические рекомендации по проведению инвентаризации и аудита, приказ об утверждении инвентаризационной комиссии;

- процедуры решения:

1. Инвентаризация объектов ИС

2. Аудит и выявление жизнеспособных объектов

3. Определение фактов хозяйственной деятельности с ОИС.

4. Анализ отчётности за последний отчетный период 


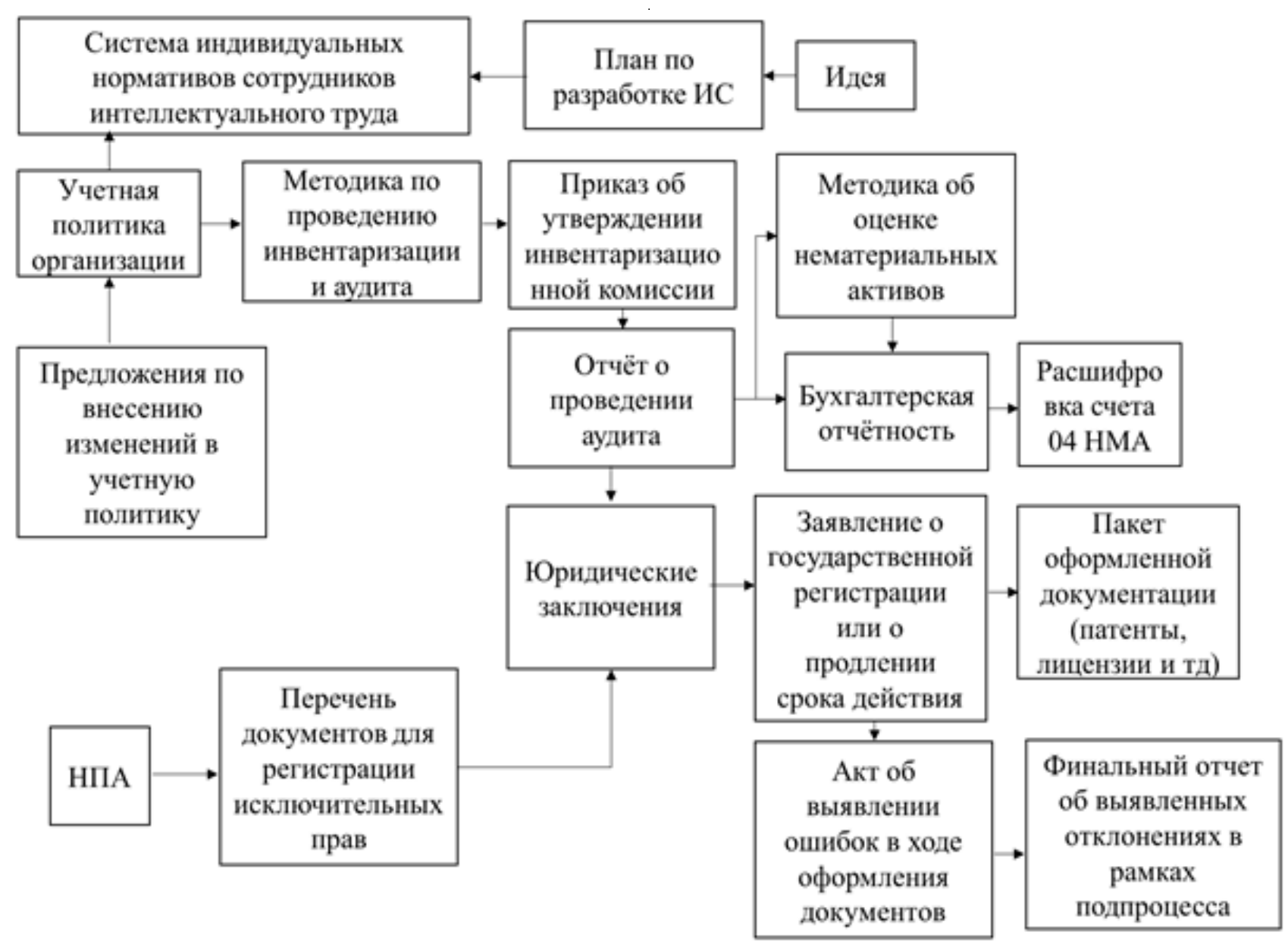

Рис. 1. Модель документооборота подпроцесса управления интеллектуальной собственностью

5. Заполнение форм бухгалтерской отчетности

6. Формулирование годового отчета с комментариями

- выходные документы: бухгалтерский баланс, расшифровка счета 04.

Документооборот во время осуществления задачи контроля интеллектуальной собственности имеет разную направленность: в первом случае контроль выступает как функция менеджмента, выражающаяся в сравнении фактических значений с плановыми, с дальнейшей фиксацией этапа, на котором обнаруживаются отклонения. С другой стороны, это контроль за сохранностью прав на ИС.

Для того, чтобы осуществлять контроль за управлением ИС необходимо разрабатывать политику по двум основным направлениям: внутреннему и внешнему.

Внутреннее подразумевает анализ результативности сотрудников, соблюдение плана, правил и нормативов, принятых в организации, а также выявление возможных отклонений, происходящих на каждом из этапов.

Как отмечалось ранее, несмотря на имеющиеся в организации надлежаще оформленные документы право на ИС может быть нарушено третьими лицами, не имеющими отношения к организации в целом, и к разработчику в частности. В данном контексте основной целью контроля является контроль правовой защищенности ИС.

Далее рассмотрим технологию проведения контроля интеллектуальной собственности со стороны непоколебимости исключительных прав:

- входные документы: законодательство, регулирующее политику в области ИС, учетная политика организации, методические рекомендации по проведению контроля ИС, приказ об утверждении контролирующей проверки комиссии;

- процедуры решения:

1. Получение запроса о возможном посягательстве на интеллектуальные права; 
2. Принятие решение о проведении контроля;

3. Организация проверки;

4. Отчет о выявленных нарушений прав на ИС;

5. Формирование перечня мероприятий по устранению отклонений.

- выходные документы: отчет о выявленных нарушениях интеллектуальных прав.

Таким образом, авторами был составлен список документов, необходимых для осуществления подпроцесса управления интеллектуальной, собственностью, а также основных функциональных задач управления.

На основании данной информации авторы схематично изобразили модель документооборота рассматриваемого подпроцесса (см. рисунок).

Таким образом, в ходе работы авторами был рассмотрен процесс управления инновациями в организации, а также входящий в него подпроцесс управления интеллектуальной собственностью.
На примере ключевых функциональных задач управления были описаны необходимые для их осуществления функции. Авторами были установлены основные атрибуты: атрибуты деятельности предприятия, ресурсы и обеспечивающие данную деятельность атрибуты.

В ходе работы авторами была построена модель документооборота подпроцесса управления интеллектуальной собственностью и было отмечено, что документооборот при реализации подпроцесса управления интеллектуальной собственностью очень важен, так как имеет множество теоретических аспектов и требует четкой регламентации (алгоритмизации) действий. Также был сделан вывод, что многие этапы данного процесса требуют получения заключений юристов, позволяющих подтверждать правомерность осуществляемых действий, что в свою очередь требует соответствия правилам, например, учетной политике, методикам другим внутренним нормативным документам.

\section{ЛИТЕРАТУРА}

1. Зубкова О.В., Бутрин А.Г., Маскайкина Е.В. Теоретико-методологические подходы к оценке инновационного процесса субъекта хозяйствования // Социум и власть. - 2019. — № 6(80). - С. 99-110.

2. Герасимов К.Б., Шкодина Е.С. Функциональное содержание управления интеллектуальной собственностью в организации // Журнал исследований по управлению. - 2021. - Т. 7.— № 2.—C. 23-29.

3. Новикова Н.А. Механизм управления инновационной деятельностью промышленного предприятия: дис. ... канд. экон. наук. — СПб., 2017. — 202 с.

4. Гишкаева Л.Л., Черхигов И.Р. Инновационные процессы в Российской экономике // Экономика и бизнес: теория и практика.— 2020.- № 121(70). - C. 190-193.

5. Шевцов В.В., Калугин Д.А. От инновационных продуктов и процессов к инновационным бизнес-моделям // Московский экономический журнал.2020. - № 11. - C. 26.

6. урбатова В.В., Черникова А.Е. Инновационный процесс: понятие, особенности внедрения // Инновационная экономика: перспективы развития и совершенствования. - 2018. — № 6(32). - С. 86-92.

7. Степаненко Д.М. Инновационный процесс и инновационная деятельность: понятие, сущность, характеристики // Проблемы современной экономики. - 2009. 一 № 4(32). - С. 36-40.

8. Чейз Р., Джейкобз Р., Аквилано Н. Дж. Производственный и операционный менеджмент.- М.: Вильямс, 2018. - 1094 с.

9. Герасимов Б.Н. Методологические инструменты науки управления в социальных и экономических средах // Менеджмент и бизнес-администрирование. - 2020. — № 4. - С. 4-17.

10. Антонец В.А., Ершов С.Н., Нечаева Н.В., Рябчиков А.П. Процессы управления интеллектуальной собственностью в проектах НИокТР (на примере Нижегородского государственного университета) // Инновации. - 2005. — № 5(82). - С. 50-54.

11. Герасимов Б.Н. Исследование и развитие функционального подхода в процессах управления экономическими системами // Менеджмент и бизнес-администрирование. - 2019. — № 4. - C. 4-14.

12. Самарина Ю.С., Шкварова А.С. Труд научных работников: применимо ли нормирование? // Наука. Инновации. 0бразование.- 2017.— Т. 12.— № 3. - C. 61-75.

( Герасимов Кирилл Борисович ( 270580@bk.ru ), Шкодина Елизавета Сергеевна ( shkodina.elizaveta@yandex.ru ).

Журнал «Современная наука: актуальные проблемы теории и практики» 